197

ARS Leopoldo Waizbort*

ano 16

ก. 32

Artigo inédito

palavras-chave:

dança; amor; paraíso

keywords:

dance; love; paradise

\section{Cheek to cheek: Ginger e Fred vão ao paraíso}

Cheek to cheek: Ginger \& Fred go to paradise
O ensaio interpreta uma cena do filme Top Hat, de 1935, na qual Ginger Rogers e Fred Astaire dançam "Cheek to cheek", e discute o significado da dança e o mundo criado pelos seres dançantes.

The essay interprets a scene from the 1935 movie Top Hat, in which Ginger Rogers and Fred Astaire dance cheek to cheek, and discusses the meaning of the dance and the world created by the dancing beings. 
A cena de Top Hat, filme da RKO de 1935, dirigido por Mark Sandrich, em que Ginger Rogers e Fred Astaire dançam "Cheek to cheek” encanta geração após geração. Onde há encanto, há mistério; neste caso, não para ser desvelado, mas para ser vislumbrado, percebido e até mesmo vivido.

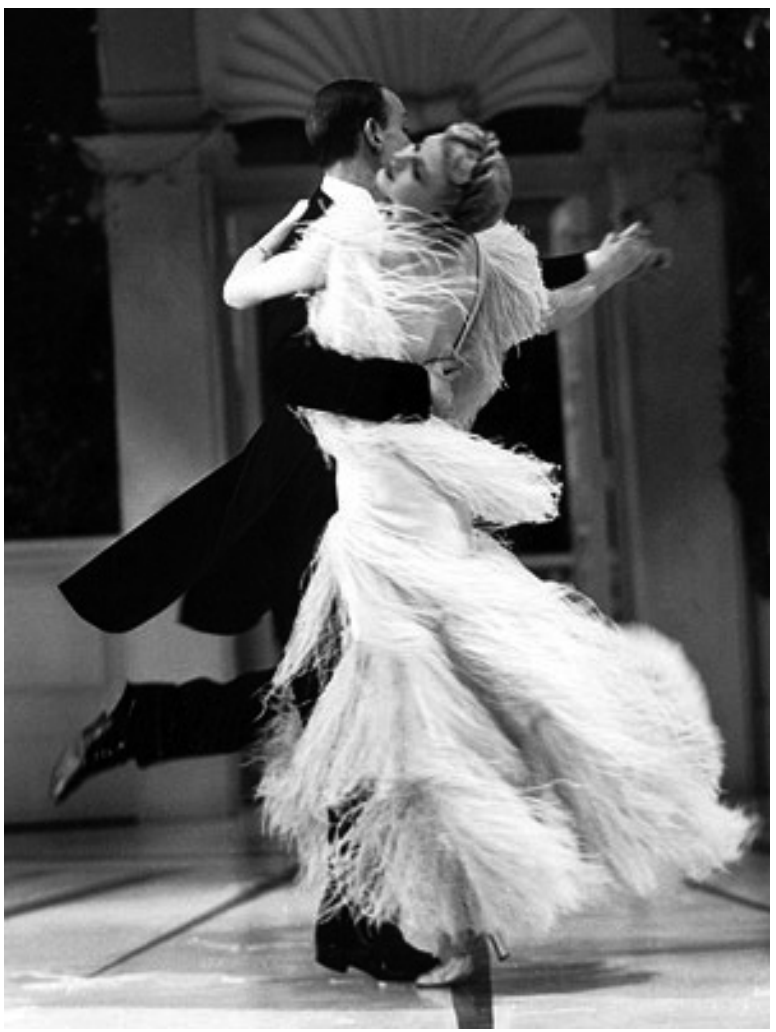

Fig. 1

Still de Top Hat (1935), Mark Sandrich, EUA.

Haveria muito a falar a respeito da cena ${ }^{1}$ : o figurino, tanto dela como dele; a canção, uma obra-prima de Irving Berlin e do cancioneiro norte-americano, notável em tantos aspectos; o intérprete, à primeira audição modesto e de parcos recursos, mas de fato o contrário disso, com seu domínio ímpar de sutilezas rítmicas e de entoSandrich. Los Angeles: RKO Pictures, 1935. $101 \mathrm{~min}$. A cena em questão ocorre aproximadamente entre 1'01" e 1'10". ação que o colocam entre os grandes intérpretes da canção norte-americana; a cenografia, tão característica dos anos entreguerras; a fotografia, que modaliza a oposição onipresente de branco e preto, e assim por diante. E, claro, para todos os que ficam tentados a situar o 

mas, como já se disse, "on high heels".

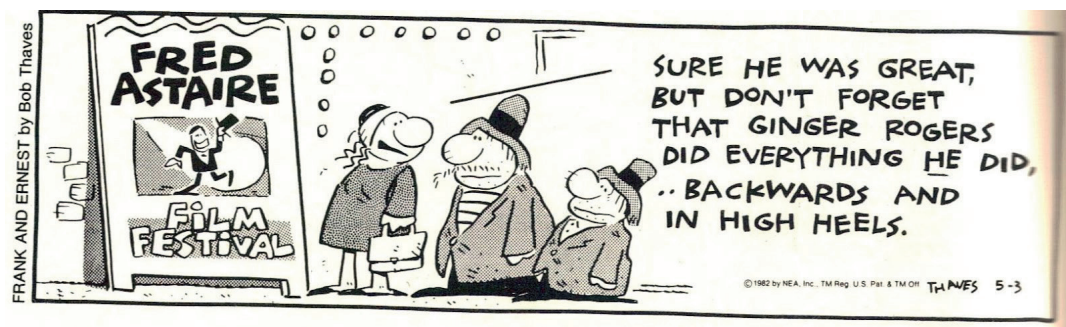

2. SOUZA, Gilda. Notas sobre Fred Astaire. In: ideia e o figurado. São Paulo: Duas Cidades; Editora 34, 2005, p. 171-177.

3. Para o assunto, ver, em ordem de relevância:

KLEINER, Gerd. Die verschwundene Anmut. Frankfurt am Maim: Peter Lang, 1994; KLEINER, Gerd. Verbete Anmut/Grazie. In: BARK, Karlheinz, FONTIUS Martin, SCHLENSTEDT Dieter et al. (eds.) Ästhetische

Grundbegriffe: historisches Wörterbuch in sieben Bänden. Stuttgart: Metzler, 2010, vol. 1, p. 193-208; FAUTH, Wolfgang. Verbete charites. In: ZIEGLER, Konrat e SONTHEIMER, Walther (eds.). Der kleine Pauly: Lexikon der Antike in fünf Bänden. München: Deutscher Taschenbuch, 1979, vol. 1, p. 1135-1137; TONELLI, G. e ABERLE, H. Grazie, Anmut. In: RITTER, Joachim e GRÜNDER, Karlfried (orgs.). Historisches Wörterbuch der Philosophie. Basel; Stuttgart: Schwabe, 1974, vol. 3, cols. 866-871.
Em suas curtas "Notas sobre Fred Astaire", Gilda de Mello e Souza menciona apenas nas linhas finais a ideia de "graça" que, contudo, é o centro aglutinador de seus argumentos, dispondo a força secreta de sua interpretação. Não por acaso, ao iniciar seu texto, a autora fala da "beleza do gesto - pura, livre, autônoma e descarnada". Sem mencionar, é de "graça" que se fala; mas somente ao final ela a revela em letra: "gesto puro, graça pura, arte pura"

Decerto, um conceito caro à estética; caberia apenas lembrar que a ideia de "graça" passa por um longo processo de verdadeiras inversões warburguianas, de seu caráter dionisíaco para o apolíneo (pensando no uso que Aby Warburg fez da polarização nietzscheana), de sua origem, enquanto divindade ligada à agricultura, como dádiva, passando por sua moralização e alegorização, já em Sêneca, e sua cristianização, na qual a charis matriarcal e ctônica transforma-se na "graça" patriarcal e monoteísta. A partir de então, sobretudo o Setecentos a explora em minúcia, seja na intensificação de sua moralização (como na conjugação de beleza e virtude), seja nos seus encantos e idílios, oferecendo o sentido com o qual a reencontramos: a beleza, a delicadeza e o encanto do movimento, que escapam à definição precisa e se apresentam como um "je ne sais quoi”’

Por essa razão, encontramos naquela dança uma espécie de atualização da "graça” para os tempos que correm (e já lá se vai quase um século: não é acaso que Michael Jackson tenha copiado Fred Astaire): uma descida das alturas do sublime para o mundo cotidiano no qual vivem homens e mulheres de carne e osso.

Daí a contraposição ao balé clássico, alocado no regime do sublime. Daí ser Astaire - mais do que toda a variedade e riqueza que a dança moderna do século XX (digamos: de Nijinsky a Pina) consumou o mais vibrante dançarino do mundo moderno, porque, além de tudo, levou a graça ao cinema, e com isso a todos os cantos do mundo e, como já dito, a gerações após gerações. 


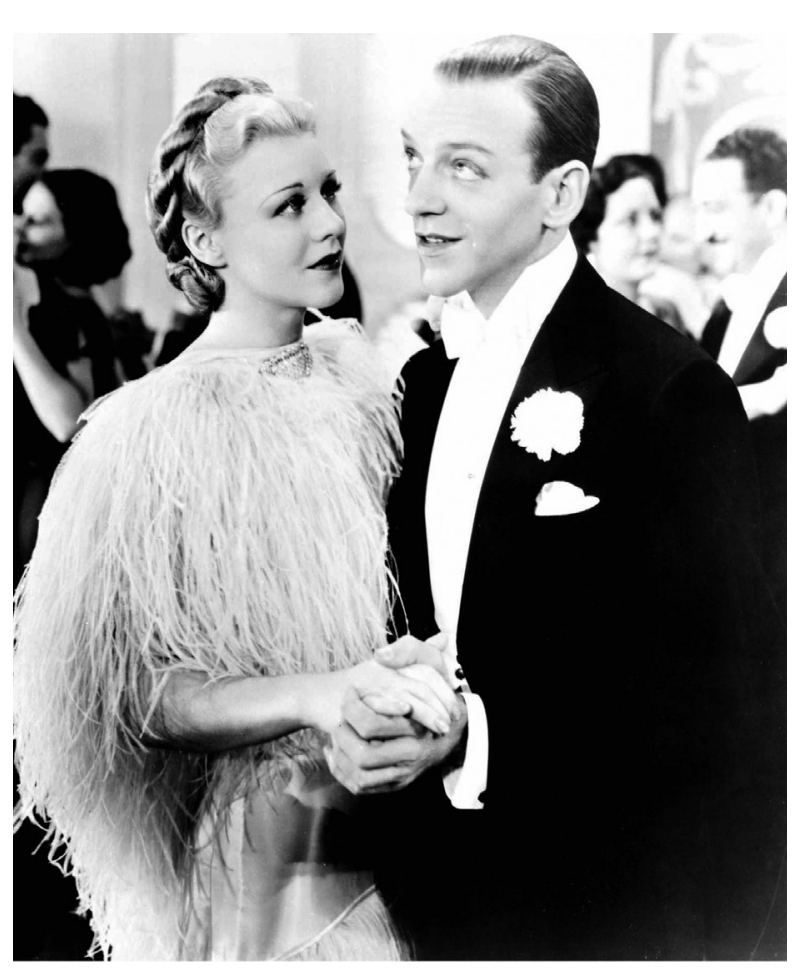

Uma "nova graça", portanto.

Essa graça "é o ato puro das metamorfoses", como nos ensina Valéry ${ }^{4}$, conduzindo-nos a um mundo em processo, dinâmico, que vai deixando para trás o que foi e vai se abrindo a cada novo passo para o que será; mas esse é, novamente, o mundo concreto dos homens, em constante transformação: o mundo histórico. Testemunhamos no dançar de Ginger e Fred essa metamorfose do conceito de graça rumo ao mundano, concreto, vivo e pulsante, histórico.

Não deve haver dúvidas sobre isso, o que, ademais, é reforçado pela gestualidade dos dançarinos: uma gestualidade que, apesar de coreografada, irrompe para além do planejado e o implode de dentro, vibrando a vida vivida, e muito concreta, dos amantes que ali dançam.

Esse é o seu primeiro segredo: os amantes, dançando, transformam, são a metamorfose em ato puro.

É por essa razão que encontramos, ali, um gesto que está nas antípodas do balé sublime, e que será, cada vez mais, ao longo do século que findou, transposto para quase todas as formas de dançar. Um casal comum, que transfigura sua mundanidade radical em graça. Nesse movimento, atualiza-a e a traz para um mundo que é o nosso, e onde já se tornara difícil reencontrá-la. Eis o seu gesto radicalmente moderno, novamente: vivo e vibrante.
200

\section{Leopoldo Waizbort}

Cheek to cheek: Ginger e Fred vão ao paraíso.

Fig. 3

Still de Top Hat (1935), Mark Sandrich, EUA.

4. "Não sentis que ela é o ato puro das metamorfoses?". VALÉRY, Paul. A alma e a dança e outros diálogos. Rio de Janeiro: Imago, 1996, p. 48. 


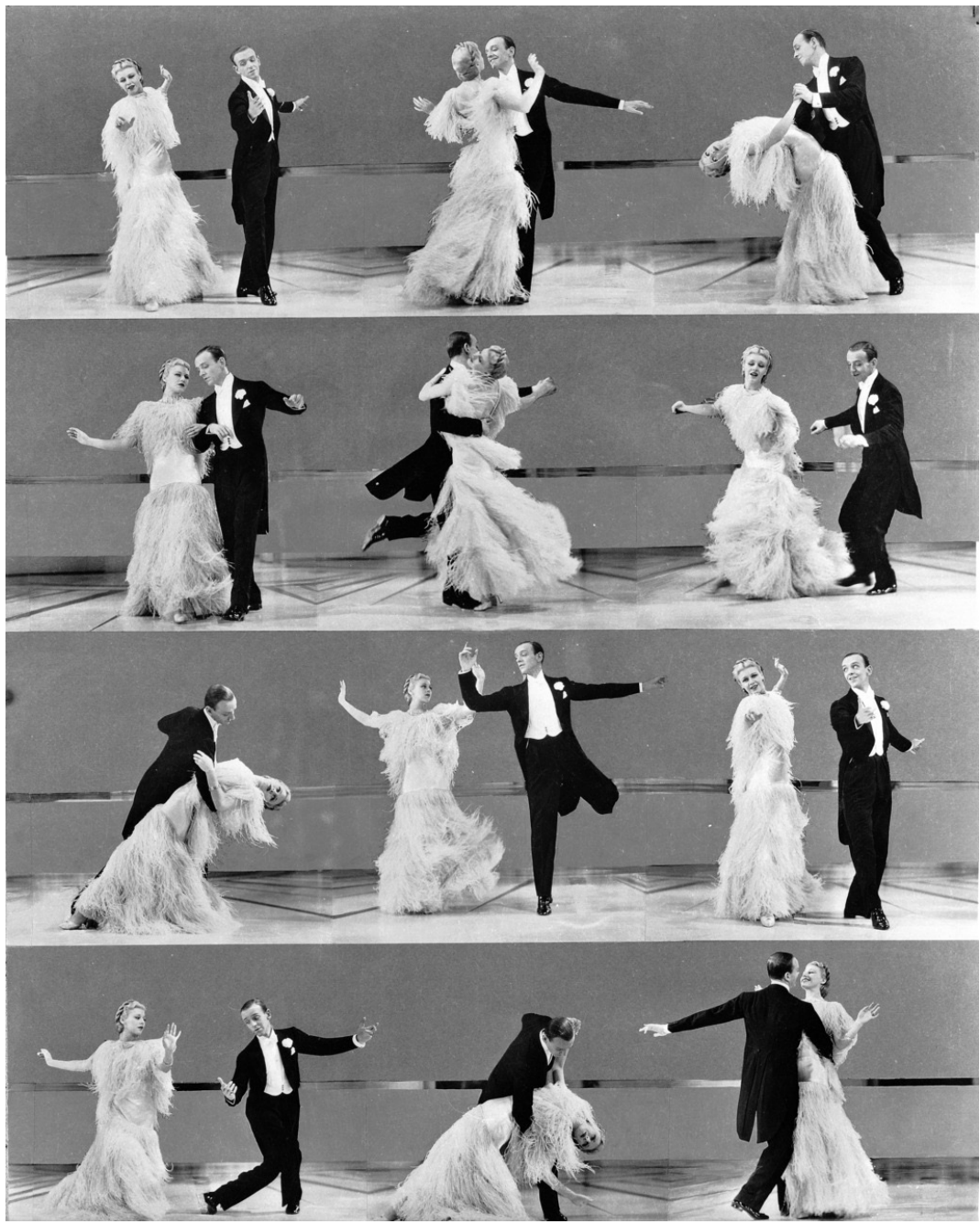

A outra forma que ali se encorpa é o lúdico e álacre. Quando Ginger dá um tapa na cara de Fred, ele nos diz: "She loves me!".

Essa passagem, a percepção do lúdico e álacre como concretiza-

5. Sobre essas questões, cf. GEBAUER, Günter e WULF, Christoph. Mimesis: Kultur, Kunst, Gesellschaft. Reinbek Rowohlt, 1992; Idem. Spiel, Ritual, Geste: mimetisches handeln in der sozialen Welt. Reinbek: Rowohlt, 1998; assim como WAIZBORT, Leopoldo. 0 beijo dos amantes. In: BUENO, Maria e CAMARGO, Luiz (orgs.).

Cultura e consumo: estilos de vida na contemporaneidade.

São Paulo: Senac, 2008, p. $247-257$ ção, ou melhor, corporificação hodierna da graça, coloca-nos no centro de uma constelação, da qual não falarei, que abarca uma teoria da mimese (na qual a dimensão lúdica e o jogo desempenham papel decisivo), da dança, do paraíso e dos amantes 5 .

Mas não deve haver dúvida de que a dança, cheek to cheek, instaura o paraíso dos amantes, que aliás é aquilo de que mais se fala na canção: "Heaven / I'm in heaven", E, claro: "Dance with me / I want my arm above you / The charm above you / Will carry me through to Heaven".

A criação do paraíso consuma-se na passagem, em meio à dança, em que os amantes saem do salão de baile - o ambiente da sociabilidade 
por excelência - e, atravessando uma pequena ponte, chegam a uma sacada onde somente eles vivem e dançam. Espacialmente cria-se um outro mundo, no qual eles estão completamente livres para dançar a dança que é somente deles - e não mais a dança comum, que os outros dançam. Se no salão dançavam como todos e eram um casal em meio a muitos - e, nesse sentido, desprovidos de singularidade absoluta - agora são só eles, o mundo é só deles, é o mundo deles. E dançam. Dançam até o limite. Dançam até onde é possível dançar. O paraíso dos amantes faz-se na dança, pela dança, é dança.

A letra da canção reitera essa interpretação:

And my heart beats so that I can hardly speak;

And I seem to find the happiness I seek

When we're out together dancing cheek to cheek.

Isso nos revela que não falo mais de Fred Astaire nem de Ginger Rogers, mas sim dos amantes que dançam. Interessa menos o dançarino, e mais o casal. Fred sem Ginger nada mais é. Talvez mais ainda, foi Ginger quem imprimiu de modo definitivo, porque puro e completo, o amor naquela dança: observem seu peito arfante ao final, quando se recostam no parapeito; ou então o seu olhar durante todo o tempo, desde que é por ele enlaçada ao início da dança; assim como suas mãos. Toda sua gestualidade e corporeidade, quando não totalmente absorvidas pelos movimentos da dança, foram deslocadas para essa expressividade, que Astaire, é preciso dizer, não alcança. É como se ele se diluísse e anulasse por completo em sua dança e em dançar com Ginger, enquanto ela, talvez por ser reticente, talvez por exercer a contragosto uma resistência, talvez por ser encantadora, resguarda um não-sei-que com o qual seu amor e sua paixão afloram.

Valéry, que tentou abordar o problema de difícil resolução, vem em nosso auxílio:

"Ela era então o ser mesmo do amor! - Mas que é ele? - De que é feito? Como defini-lo e pintá-lo? Bem sabemos que a alma do amor é a diferença invencível dos amantes, enquanto que tem por matéria sutil a identidade de seus desejos. É preciso então que a dança faça nascer, pela sutileza dos traços, pela divindade dos ímpetos, pela delicadeza das pontas paradas, essa criatura universal que não tem corpo nem rosto, mas que tem dons, e dias, e destinos; mas que tem uma vida e uma morte; e que nada mais é afinal que vida e morte, pois o desejo, uma vez criado, não conhece sono nem trégua
Leopoldo Waizbort

Cheek to cheek: Ginger e Fred vão ao paraíso. 
6. VALÉRY, Paul. Op. cit., p. 46.0 nexo de dança e amor também foi explorado em texto clássico de Havelock Ellis, em ELLIS, Havelock. The dance of life (trecho). In: COPELAND, Roger e COHEN, Marshall (eds.). What is dance? readings in theory and criticism. Oxford: Oxford University Press, 1983, p. 478-496.

Fig. 5 Still de Top Hat (1935), Mark Sandrich, EUA. seus belos atos. Ela inteira, Sócrates, inteira, era o amor!”6.

Eis como sucede a síntese única que cria algo que transcende os dois, e que é, nada mais e nada menos, o paraíso dos amantes.

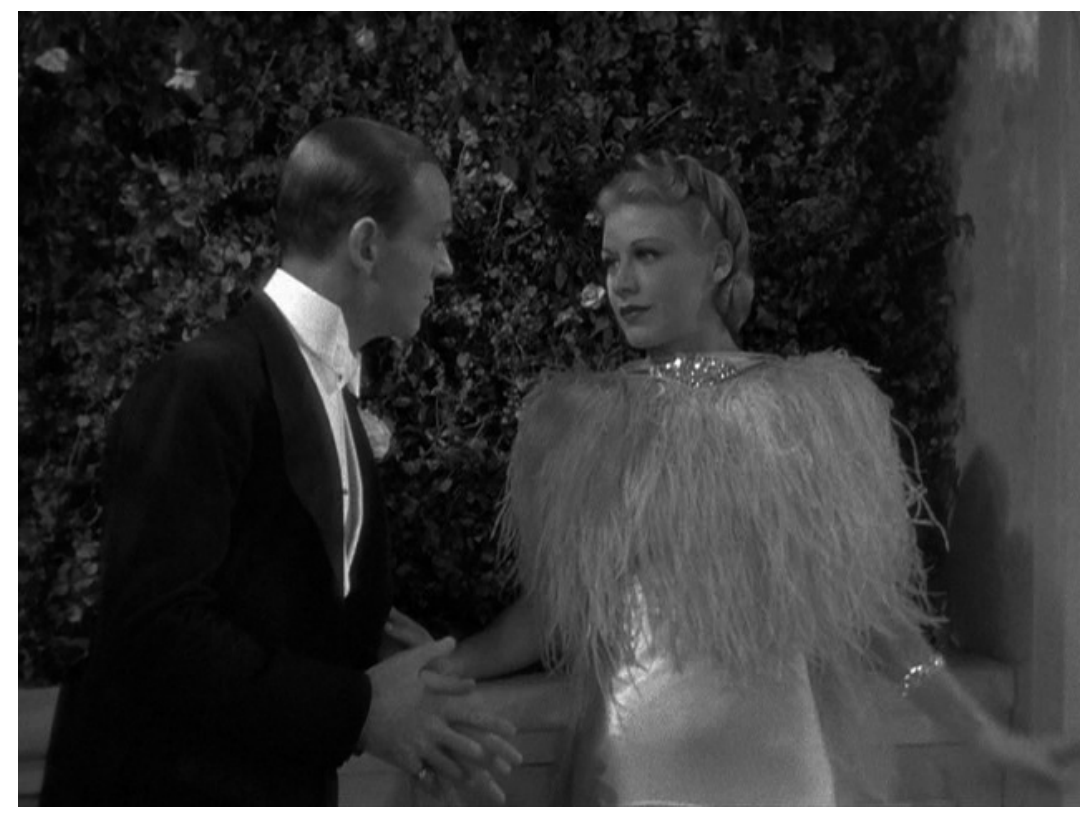

É Ginger, e não Fred, quem conduz, embora o primeiro olhar possa nos enganar e levar a crer no contrário - inclusive a história, na qual o cavalheiro sempre e necessariamente conduz a dama. Com isso, podemos afirmar que a reatualização da graça talvez não se deva ao argumento anterior, mas sim a essa inversão, subversão histórica, verdadeiro acontecimento, o protagonismo amoroso dela. É ela, e não ele, que traz o moderno.

Nessa altura, vale notar que, seguindo o padrão de dessexualização da graça, apenas sugerido mais acima, sobretudo com relação ao século XVIII, a dupla Ginger e Fred situa-se em polos opostos, pois não se vê sexo algum no dançarino, quando muito um difuso desejo desprovido de sexo, enquanto Ginger toma para si - peito arfante de desejo, gozo que somente pode se consumar na união dos corpos dançantes, olhar que não deixa dúvidas de uma paixão que arde sem parar, mãos que se crispam no espaço para não agarrar o seu amado - tudo o que se permitia exprimir a respeito do assunto na Holywood dos anos 1930. Que, como se vê, não era pouco. 
No poema de Drummond, "A dança e a alma", em jogo com Valéry, algo disso é vocalizado:

A dança? Não é movimento, súbito gesto musical.

É concentração, num momento, da humana graça natural.

No solo não, no éter pairamos, nele amaríamos ficar.

A dança - não vento nos ramos: seiva, força, perene estar.

Um estar entre o céu e o chão, novo domínio conquistado, onde busque nossa paixão libertar-se por todo lado...

Onde a alma possa descrever suas mais divinas parábolas sem fugir à forma do ser, por sobre os mistérios das fábulas.

A atualização da graça, que havia mencionado, concretiza-se no que seria um equivalente dançante do "sermo humilis", tão bem demonstrado por Erich Auerbach. O mais concreto conquista a maior expressividade, síntese em forma de dança. A corporeidade ali criada, nos corpos ardentes dançantes, corpos que se entendem, é a criação desse "novum". Aqui haveria, se é permitido elucubrar, uma interversão dialética: se havia antes apenas o mundo presente, há agora um outro mundo, o dos amantes, que se usa denominar paraíso.

Consumando a graciosidade de que falava Kleist ${ }^{7}$, suspensos, dançantes, entre a terra e o céu, como nos quadros em que Chagall se retratou com sua muito amada Bella, insuflados pelo sopro do amor, o vento selvagem do amor, gravitando contra a lei da gravidade, muito além de todas as leis, livres, completamente livres, eles se tornaram pura graça, indiferenciados, fusão de corpo com corpo, amantes no paraíso.
Leopoldo Waizbort

Cheek to cheek: Ginger e Fred vão ao paraíso.
7. Cf. VON KLEIST, Heinrich. Über das Marionettentheater. In: Sämtliche Werke und Briefe. 7. ed. München: Carl Hanser, 1984, vol. 2, p. 338-345. 
Fig. 6

Marc Chagall, 0 passeio, 1917-18, óleo sobre papel, 170 X 163,5 cm, Museu Russo, São Petersburgo.

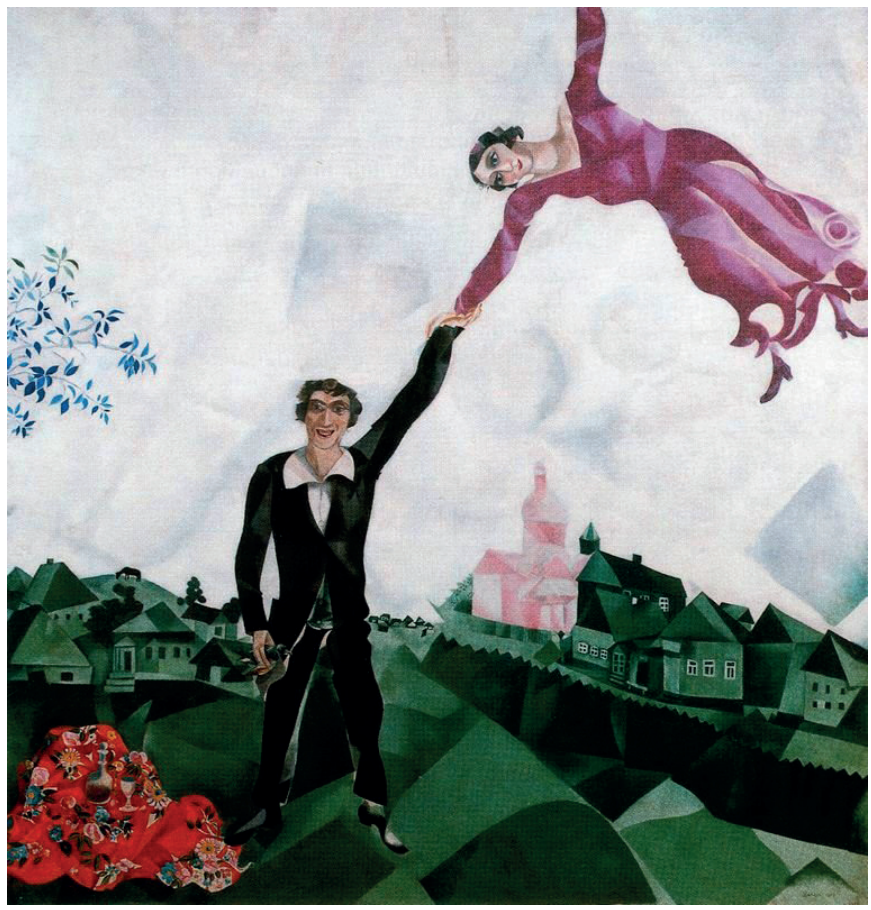

Fig. 7

Marc Chagall, Sobre a cidade, 1914-18, óleo sobre tela, 141 X $198 \mathrm{~cm}$, Galeria Tratjakow, Moscou.

Artigo recebido em 5 de dezembro de 2017 e aceito em 24 de janeiro de 2018.

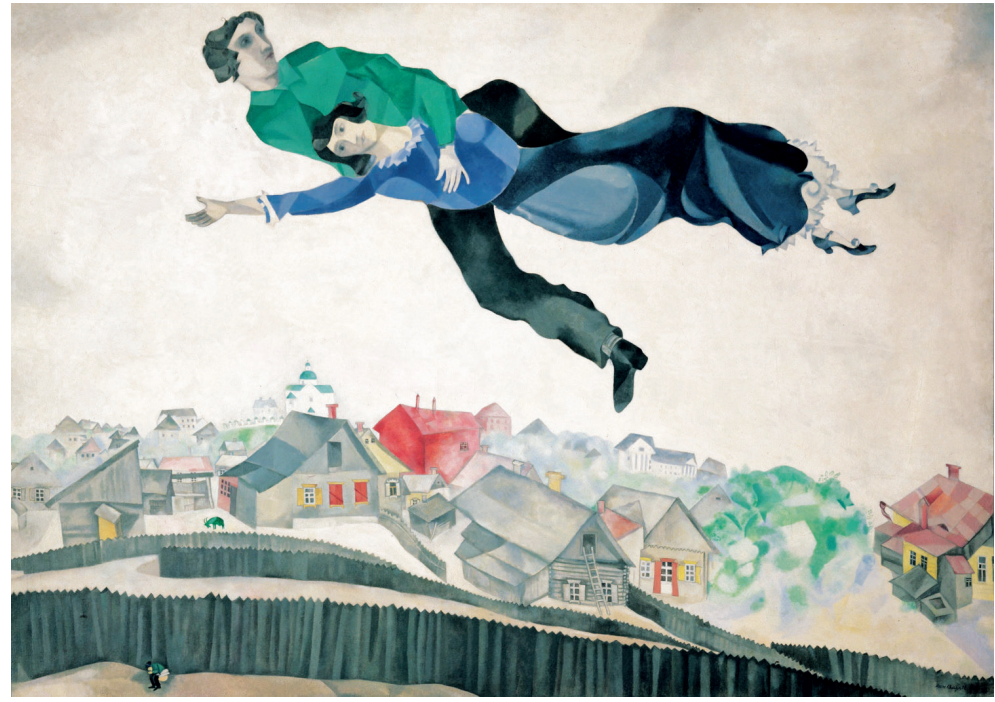

Leopoldo Waizbort é graduado em ciências sociais pela Universidade de São Paulo (1987), onde realizou mestrado (1992), doutorado (1996) e livre-docência (2003). Desde 2010 é professor titular na mesma universidade. Trabalha na área de sociologia, com ênfase em teoria sociológica, sociologia da cultura, história da sociologia, antropologia histórica e sociologia da música. 